\title{
27
}

\section{Using Case Study Research to Build Theories of IT Implementation}

\author{
G. Paré \\ École des Hautes Études Commerciales \\ 3000 chemin de la Côte-Ste-Catherine \\ Montréal, Québec, Canada \\ Tel: (514) 340-6812 \\ Fax: (514) 340-6132 \\ E-mail: Guy.Pare@hec.ca
}

\section{J. J. Elam}

Florida International University

Miami, Florida, United States

Tel: (305) 348-2719

Fax: (305) 348-3278

E-mail: Elamj@servax.fiu.edu

\begin{abstract}
In this paper, we present and illustrate how the approach proposed by Eisenhardt (1989) for building theories from case study research can help researchers understand and explain the inherently dynamic nature of numerous IT phenomena. The approach, which adopts a positivist view of research, relies on past literature and empirical data as well as on the insights of the researcher to build incrementally more powerful theories. We describe in some detail how this methodology was applied in a particular research study on IT implementation and how the use of this approach contributed to the discovery of a number of new perspectives and empirical insights. Furthermore, we discuss when it is appropriate to follow, to ignore, or to modify the suggestions made by Eisenhardt.
\end{abstract}


Overall, using Eisenhardt's approach as a starting point, our objective is to provide a more complete and detailed guide for using case studies to build theories within the MIS field.

\section{INTRODUCTION}

Information technology (IT) implementation has constituted a central and growing issue of research in the IS field. There is extensive literature on IT implementation dating back to the 1970s (e.g., Swanson 1974; Robey and Zeller 1978; Lucas 1978) with a growing number of studies conducted in the late 1980s and early 1990s (e.g., Srinivasan and Davis 1987; Leonard-Barton 1988; Lucas, Ginzberg, and Schultz 1990; Sabherwal and Robey 1993). The IT implementation stream of research consists primarily of studies, often referred to as "factor studies," which have tried to identify factors believed to be relevant to IT implementation success. Even though these studies have substantially contributed to our understanding of IT implementation, there are limitations inherent in the factor approach employed. First, these studies can only realistically handle a subset of the pieces of the implementation puzzle (Swanson 1988) and hence have caused a greater fragmentation of our understanding of the phenomenon (Kwon and Zmud 1987; Wynekoop 1992). Second, and most important, the factor approach has not provided much insight into the dynamics of the implementation process, that is, how and why independent variables interact and affect project outcomes (Newman and Robey 1992; Elam, Prescott and Wasala 1994).

In short, researchers have built models that identify a limited set of critical factors affecting IT implementation success, but we know very little about how and why the factors included in these models interact and work together to produce success or failure. As a result, MIS researchers lack a full understanding of the IT implementation process that is necessary to guide practitioners to attain positive outcomes. It thus appears important to ask ourselves, as researchers, how to improve not only our research models, but also our methodologies so that the results of our work can be of greater value to practitioners.

IT implementation is a complex, dynamic process involving diverse groups of key actors and activities. Researchers, tired of conflicting, ambiguous results, are seeking new methods with which to explore this process. For instance, Newman and Robey introduced an episodic-mapping methodology and demonstrated how it could be used to study the development of computer-based information systems. This methodology was then applied to a fifteen year systems implementation effort within a single organization, demonstrating its value in identifying and tracking important events, and highlighting patterns that recurred over time (Robey and Newman 1996). These researchers were motivated by the desire to utilize a methodology specifically designed to accommodate the intricacies of the IT implementation process, and they did indeed succeed in capturing the interplay of diverse groups and perspectives. 
As another example, Elam, Prescott and Wasala conducted an in-depth case study that followed the implementation of an emerging IT over an eighteen month period. The study assessed the extent to which characteristics traditionally associated with successful implementation efforts were present in this implementation. It was found that only some of these characteristics were present at only certain times during the implementation period. To explore why this particular implementation was successful, a model was developed that showed the ways in which these ideal characteristics interacted. This interaction model was then used to explore how the presence of some characteristics compensated for the absence of others. Importantly, findings from this study revealed how mixed patterns involving factors at different levels complicate traditional statistical analysis that conceives of a direct association between implementation predictors and outcomes.

From these "innovative" studies, it clearly appears that further progress will require more complex, realistic research models and the development of alternative perspectives for viewing IT implementation. In this paper, we present and illustrate how the approach proposed by Eisenhardt (1989) for building theory from case study research can help researchers understand and explain the inherently dynamic nature of the IT implementation process. Several pieces of the approach proposed by Eisenhardt are borrowed from extant literature. In this regard, the approach includes key ideas and concepts from the work of Glaser and Strauss (1967) on grounded theory, Yin (1984) on case study research, Miles and Huberman (1984) on qualitative data analysis, Van Maanen (1988) on ethnography and Jick (1979) on triangulation of data types, to name a few. While these previous writings provide pieces of the process and focus on defending building theory from cases, the work of Eisenhardt focuses on how to actually build theory from cases. The approach relies on past literature and empirical data as well as on the insights of the researcher to build incrementally more powerful theories. It adopts a positivist view of research in that it is based on predefined research questions, a consideration of a priori constructs, and "it is directed toward the development of testable hypotheses and theory which are generalizable across settings" (Eisenhardt 1989, p. 546). Importantly, the final product of this approach may be the discovery of one or more emerging concept, the development of a new conceptual framework or the refinement of an existing one, or the development of a set of research propositions or possibly a mid-range theory.

In order to provide a practical demonstration of how the approach proposed by Eisenhardt can be used in studying IT implementation, this paper illustrates it with extensive material taken from an actual, published IT implementation case study (Paré 1995; Paré and Elam 1996; Paré, Elam and Lima forthcoming). This in-depth case study examines the implementation process, use, and consequences of three clinical information systems at a large tertiary care teaching hospital.

We show that the Eisenhardt approach to theory-building using case study research can be successfully applied in an IT context and can contribute to the discovery of new phenomena. In addition, we provide insights into the many choices that a researcher must make when adopting this approach. We discuss when it is appropri- 
ate to follow, to ignore, or to modify the suggestions made by Eisenhardt. Using Eisenhardt's approach as a starting point, our objective is to provide a more complete and detailed guide for using case studies to build theory within the IS field.

\section{A CASE STUDY APPROACH TO STUDYING IT IMPLEMENTATION}

This section describes the "roadmap" proposed by Eisenhardt for building theories from case study research and illustrates how this methodological framework can serve as a useful guide to researchers interested in studying the complex and dynamic nature of IT implementation. The roadmap is summarized in Table 1.

\subsection{Step 1: Getting Started}

According to Eisenhardt, three issues are of great importance in getting started: the initial definition of research questions, the a priori specification of constructs, and the consideration of a priori theory or hypotheses. Each of these issues will be examined in turn.

\section{Initial Definition of Research Questions}

First, an initial definition of one or more related research question, in at least broad terms, is as important in building theory from case studies as it is in hypothesis-testing research. Without a research focus, it is easy to become overwhelmed by the volume of qualitative data.

The ultimate intent of our study was to broaden and strengthen our understanding of IT implementation by researching the dynamic nature of the implementation process. More specifically, efforts were directed toward opening the black box and providing the story that explains how and why contextual conditions and implementation tactics and strategies interact and work together to produce project outcomes. In pursuit of this objective, two interrelated research questions were initially stated:

To what extent is the "ideal" implementation scenario a necessary condition to success? Referring to Swanson's metaphor (1988), to what extent should all the pieces of the "puzzle" be present and "fit" together to ensure implementation success?

What are the laws of interaction which characterize the dynamic nature of IT implementation? How do contextual conditions and implementation tactics interact and work together to ensure system success?

These research questions provided a well-defined focus to our research study and permitted us to specify the kind of data to be gathered. 
Table 1 Process Building Theory from Case Study Research (Eisenhardt 1989).

\begin{tabular}{|c|c|c|}
\hline Step & Activity & Reason \\
\hline $\begin{array}{l}\text { 1. Getting } \\
\text { started }\end{array}$ & $\begin{array}{l}\text { Definition of research } \\
\text { questions } \\
\text { Possibly a priori constructs } \\
\text { Neither theory nor hypoth- } \\
\text { eses }\end{array}$ & $\begin{array}{l}\text { Focuses efforts } \\
\text { Provides better grounding of con- } \\
\text { struct measures } \\
\text { Retains theoretical flexibility }\end{array}$ \\
\hline $\begin{array}{l}\text { 2. Selecting } \\
\text { cases }\end{array}$ & $\begin{array}{l}\text { Specified population } \\
\text { Theoretical sampling }\end{array}$ & $\begin{array}{l}\text { Sharpens external validity } \\
\text { Focuses efforts on cases that repli- } \\
\text { cate or extend theory }\end{array}$ \\
\hline $\begin{array}{l}\text { 3. Crafting } \\
\text { instruments } \\
\text { and proto- } \\
\text { cols }\end{array}$ & $\begin{array}{l}\text { Multiple data collection } \\
\text { methods } \\
\text { Qualitative and quantita- } \\
\text { tive data combined } \\
\text { Multiple investigators } \\
\end{array}$ & $\begin{array}{l}\text { Strengthens grounding of theory } \\
\text { by triangulation of evidence } \\
\text { Synergistic view of evidence } \\
\text { Fosters divergent perspectives and } \\
\text { strengthens grounding }\end{array}$ \\
\hline $\begin{array}{l}\text { 4. Entering } \\
\text { the field }\end{array}$ & $\begin{array}{l}\text { Overall data collection and } \\
\text { analysis } \\
\text { Flexible and opportunistic } \\
\text { data collection methods }\end{array}$ & $\begin{array}{l}\text { Speeds analysis and reveals help- } \\
\text { ful adjustments to data collection } \\
\text { Allows investigators to take ad- } \\
\text { vantage of emergent themes and } \\
\text { unique case features }\end{array}$ \\
\hline $\begin{array}{l}\text { 5. Analyzing } \\
\text { data }\end{array}$ & $\begin{array}{l}\text { Within-case analysis } \\
\text { Cross-case pattern using } \\
\text { divergent techniques }\end{array}$ & $\begin{array}{l}\text { Gains familiarity with data and } \\
\text { preliminary theory generation } \\
\text { Forces investigators to look be- } \\
\text { yond initial impressions }\end{array}$ \\
\hline $\begin{array}{l}\text { 6. Shaping } \\
\text { hypotheses }\end{array}$ & $\begin{array}{l}\text { Replication, not sampling, } \\
\text { logic across cases } \\
\text { Search evidence of "why" } \\
\text { behind relationships }\end{array}$ & $\begin{array}{l}\text { Confirms, extends, and sharpens } \\
\text { theory } \\
\text { Build internal validity }\end{array}$ \\
\hline $\begin{array}{l}\text { 7. Enfolding } \\
\text { literature }\end{array}$ & $\begin{array}{l}\text { Comparison with conflict- } \\
\text { ing literature } \\
\text { Comparison with similar } \\
\text { literature }\end{array}$ & $\begin{array}{l}\text { Builds internal validity } \\
\text { Sharpens generalizability }\end{array}$ \\
\hline $\begin{array}{l}\text { 8. Reaching } \\
\text { closure }\end{array}$ & $\begin{array}{l}\text { Theoretical saturation } \\
\text { when possible }\end{array}$ & $\begin{array}{l}\text { Ends process when marginal im- } \\
\text { provement becomes small }\end{array}$ \\
\hline
\end{tabular}

\section{A Priori Specification of Constructs}

With respect to the issue of using existing theoretical constructs to guide theorybuilding research, two different approaches may be taken (Anderson and Aydin 1994). In the first, the researcher works within an explicit conceptual framework. A conceptual framework "consists of a selection of concepts and relations among them, 
grouped so as to enable its users to easily see the major concepts simultaneously in their relations to one another" (Kochen 1985, p. 93). Therefore, a conceptual framework becomes a "researcher's first cut at making some explicit theoretical statements" (Miles and Huberman 1994, p. 91). In the second, the researcher tries not to be constrained by prior theory and instead sees the development of relevant theory, hypotheses, and concepts as a purpose of the project. In the present study both approaches were combined since the main intent was to provide freshness in perspective to an already researched topic. Importantly, given that this study was aimed at theory building, not theory testing, the conceptual framework (and its constructs) was used solely as a starting point. Basically, it helped make sense of occurrences, ensured that important issues were not overlooked, provided a set of constructs to be investigated, and guided our interpretation and focus. Specifically, using the research questions as a guide, a conceptual framework (see Appendix 1) was developed that grouped constructs related to the contextual conditions surrounding most implementation situations (e.g., resources availability, top management support, user attitudes, system characteristics), the tactics and strategies aimed at launching the project, managing the development of the new system and preparing organizational members for the new computer application, and the different criteria commonly adopted to evaluate system success (e.g., system use, user satisfaction with system, individual consequences, satisfaction with overall implementation process). In this light, the conceptual framework developed in our research provides an insightful way to study the process of implementing information technologies. Specifically, it suggests that researchers should pay careful attention to contextual conditions, human actions (both those of the implementers and the actions of those who are the targets of the implementation), and their interaction in order to better understand IT implementation success. However, as stressed by Eisenhardt, although early identification of possible constructs allows them to be explicitly measured in interviews and questionnaires, it is equally important to recognize that the identification of constructs is tentative in theory-building research. We found this to be true as new factors were found during data collection that needed to be added to the analysis.

\section{Consideration of A Priori Theory or Hypotheses}

The objective of our research study was to develop a process theory of IT implementation. Eisenhardt suggests that theory-building research must begin as close as possible to the ideal of no theory under consideration and no hypotheses to test since preordained theoretical perspectives may bias and limit the findings. However, as stressed by Eisenhardt, it is quite impossible to achieve the ideal of a clean theoretical slate. Hence, although we followed her suggestion in terms of not identifying specific relationships between the constructs identified in our conceptual framework, we found it necessary to make use of a process meta-theory called the teleological view (Van de Ven and Poole 1995). Indeed, a caveat for existing process models raised by Mohr (1982) seems particularly relevant to IT implementation studies. Precisely, Mohr argues that it is not enough for such models to supply the succession of events 
(such as in stage models). Rather, he posits that process models must provide the external forces and probabilistic processes constituting the means by which events are understood to unfold. In accord with Mohr, we believe process explanations become more meaningful when situated within a broader or higher level of process theory. The adoption of a particular meta-theory, namely, teleological theory, reflected our basic assumptions about the nature of the phenomena being studied, assumptions that were supported by strong evidence in the data.

The teleological view of process theory shaped our study of IT implementation in three important ways. First, the implementation of a computer-based information system was conceived as a purposeful endeavor which involved movement through different states toward attaining a specific goal or desired end state. Second, there were many possible paths that could be adopted in order to fulfill a specific end goal. Third, human actions were viewed as based on the actors' perceptions of how likely it was that a particular action would move the process closer toward goal achievement. In sum, by adopting a teleological view, our theory of IT implementation cannot specify what trajectory implementation will follow. At best, we can rely on norms of rationality to prescribe certain paths. Consequently, by adopting a teleological view of IT implementation, we focused our research efforts on understanding how courses of action were selected, developing process explanations related to the movement toward attaining a desired end state, and accessing the role of human perception in making progress toward goal achievement.

The adoption of the teleological process meta-theory was of great help in focusing our research efforts at the outset of the project since it provided the frame through which we could observe the IT implementation process and identify the key events of interest out of numerous ones that were occurring. As a final remark, it should be stressed that the data gathered in this study could have been analyzed using concepts such as punctuated equilibrium, conflict, and gradualism belonging to other types of process meta-theories such as life-cycle, dialectic, and evolution. For instance, the adoption of a dialectical perspective would have encouraged the study of issues such as politics and conflict within the IT implementation process. Using this perspective, a researcher would recognize the existence of subgoals and self-interest, and would examine how participants build, maintain, lose, and challenge power bases and whether they strive to resolve conflict through open communication or whether they resort to threats and coercion.

\subsection{Step 2: Selecting Cases}

Selection of cases represents another important aspect of building theory from case studies (Lee 1989; Benbasat, Goldstein and Mead 1987; Eisenhardt 1989). Such research relies on theoretical sampling (i.e., cases are chosen for theoretical, not statistical, reasons). The cases may be chosen to replicate previous cases or extend emergent theory, or they may be chosen to fill theoretical categories and provide examples of polar types (Eisenhardt 1989). 
Given the nature of our research, we adopted a literal replication strategy where similar, not contrasting, results were predicted for each case. The number of replications is a matter of discretionary and judgmental choice (Yin 1984; Eisenhardt 1989). It depends upon the certainty a researcher wants to have about the multiple-case results. Three distinct organizational units at a large tertiary care teaching institution agreed to participate in our research project. Consequently, three independent IT implementation projects became the objects of our research.

\subsection{Step 3: Crafting Instruments and Protocols}

Theory-building researchers typically combine multiple data collection methods. The rationale is the same as in hypothesis-testing research; that is, the triangulation made possible by multiple data collection methods provides stronger substantiation of constructs and hypotheses (Eisenhardt 1989). Several MIS researchers (e.g., Wynekoop 1992; Lee 1989; Benbasat, Goldstein and Mead 1987; Kaplan and Duchon 1988) recommend that both quantitative and qualitative data be used in any study if at all possible. Collecting different types of data by different methods from different sources produces a wider scope of coverage and may result in a fuller picture of the phenomena under study than would have been achieved otherwise (Bonoma 1985).

We collected both qualitative data and quantitative data in our study. Qualitative data were primarily collected through face-to-face semi-structured interviews. As stressed by Kaplan and Maxwell (1994), the primary goal of interviews is to elicit the respondent's views and experiences in his or her own terms rather than to collect data that are simply a choice among preestablished response categories. The first step in the research design was to interview individuals who participated in the development of each of the IT implementation projects along with a small group of user representatives. Each interview started with a brief discussion of the research project, carefully designed to arouse the attention and interest of the interviewee, while not biasing the responses by providing too much information about the conceptual framework. The core of the interviews was semi-structured. Interview guides had been developed and were used during each interview. Basically, each interview guide contained the specific issues to be discussed with the respondent and questions to be kept in mind during each interview. An excerpt of an interview guide used in our study is presented in Appendix 2.

We also encouraged open discussions toward the end of each interview allowing interviewees to ask any questions and add any comments they might want. A total of 95 interviews were conducted over a period of six months. Interviews were conducted for one IT implementation project before proceeding to another. The average length of each interview was approximately 60 minutes with individuals involved in the IT implementation project and 30 minutes with user representatives producing a total of 812 pages of transcripts. Appendix 3 presents a profile of the interviewees.

Each project had been implemented within the last four years, making real time data gathering impossible. Recognizing this limitation, two tactics were adopted in 
our study to increase construct validity: reconstruction of events using multiple respondents and having key informants review final versions of reports.

Documents and texts also can be valuable sources of qualitative data (Miles and Huberman 1994; Kaplan and Maxwell 1994). For instance, in Kaplan's studies of the acceptance and diffusion of medical information systems $(1983,1987,1988)$, the author read closely original source documents such as published research papers, popularizations in medical magazines, newsletters and books, and conference reports. In line with Kaplan's work, all documents relevant to the present study, including organizational charts, annual reports, special reports and/or administrative documents, newsletters and other internal publications, user manuals and/or training material, and software vendor marketing kits were collected and analyzed. In one of the three cases, the researchers read a series of three scientific papers that had recently been published by two of the key actors involved in the implementation process. These papers present the results of a post-audit evaluation effort which took place before, during and after an anticipated four-day system failure. These documents provided precious quantitative information that could be compared with the responses of the interviewees in regard to the value of the electronic charting system over the handwritten method.

Finally, whenever possible, observation completed the qualitative assessment. Observation in qualitative studies produces detailed descriptive accounts of what was going on. Such observation often is crucial to the assessment of a system. For example, Kaplan and Duchon (1988) went to the laboratories to observe what technologists actually did, rather than simply depend on verbal reports or job descriptions. In our own study, observation took place during several training sessions and meetings involving IT implementation project team members, user representatives and external parties. Direct observation of a few clinicians using the different computerbased information systems was also possible in all three organizational units. Detailed notes were taken during all observations in order to capture the researchers' impressions and insights.

The second and last step in the research design was to gather quantitative data. As stressed by Eisenhardt, quantitative data "can keep researchers from being carried away by vivid, but false, impressions in qualitative data, and it can bolster findings when it corroborates those findings from qualitative evidence" (p. 538). Questionnaire items are often developed after the researcher has analyzed a series of interviews, observations, and documents (Kaplan and Duchon 1988). This strategy reflects a fundamental difference between case studies and alternative methods (e.g., survey, laboratory experiment, field studies). In the former, the researcher may have less a priori knowledge of what the variables of interest will be and how they will be measured (Eisenhardt 1989).

In our study, qualitative data were used primarily to develop or suggest theoretical arguments which could then be strengthened (or weakened) by quantitative support. Survey instruments were developed to collect data that would either confirm or refute our interpretation of the data. Respondents were the identified key informants, 
namely, the individuals actively involved in the three IT implementation projects who had been interviewed earlier. To ensure that the responses were valid, the surveys were administered toward the end of data collection, although complete analysis of the interview data had not been completed. The survey contained questions that were based on the preliminary data analysis and therefore had not been discussed during the interviews.

In sum, the gathering of both quantitative and qualitative data from multiple sources helped to demonstrate the extent of congruity and consistency between the researchers' and key informants' evaluations of the IT implementation projects. However, because the analysis of the interview data could not be completed prior to the administration of the surveys, some important and relevant constructs were not captured in the survey instruments developed for each case. As recommended by Leonard-Barton (1990), sufficient time should be allowed for analysis between waves of data collection in order to eliminate this problem.

\subsection{Step 4: Entering the Field}

A striking feature of research to build theory from case studies is the frequent overlap of data analysis with data collection (Eisenhardt 1989). The analytical techniques adopted in the first stage of data analysis in our own research are presented below. Note that these techniques were used to help us identify themes, develop categories, and explore similarities and differences in the data, and relationships among them.

First, field notes were an important means of accomplishing this overlap in our study. As described by Van Maanen (1988), field notes are an ongoing stream-ofconsciousness commentary about what is happening in the research. By reviewing our field notes frequently, important issues or conflicting answers provided by different individuals were identified immediately. Selected key informants were interviewed again to clear up any questions and to provide any additional information that was missing. The field notes also were useful in revising the interview guides as the study progressed. Second, once an interview was transcribed, reflective remarks were directly entered into the transcripts within brackets. These remarks were ways of getting ideas down on paper and of using writing as a way to facilitate reflection and analytic insight. They were a way to convert the researcher's perceptions and thoughts into a visible form that allows reflection (Strauss and Corbin 1990; Miles and Huberman 1994). In short, reflective remarks helped us start thinking, making deeper and more general sense of what was happening, and explaining things in a conceptually coherent way. Finally, a document summary form was created for each document collected and then filled out in the database. This form put the document in context, explained its significance, and gave a brief content summary (Miles and Huberman 1994).

In sum, overlapping data analysis with data collection not only gives the researcher a head start in analysis but, more importantly, allows researchers to take advantage of flexible data collection. Indeed, a key feature of theory-building case research is 
the freedom to make adjustments during the data collection process. In our study, adjustments included adding questions to interview guides, reviewing more data sources, observing meetings when the opportunity arose to do so, and interviewing previously unknown individuals who were identified during the study as important actors in the IT implementation projects.

\subsection{Step 5: Analyzing Data}

Analyzing data is the heart of building theory from case studies, but it is both the most difficult and the least codified part of the process (Eisenhardt 1989). Qualitative studies tend to produce large amounts of data that are not readily amenable to mechanical manipulation, analysis, and data reduction (Yin 1984). Therefore, the basic goal of qualitative data analysis is understanding, i.e., the search for coherence and order (Kaplan and Maxwell 1994). Inspired by the work of Eisenhardt, our data analysis included two aspects: "Within-Case Analysis" and "Cross-Case Analysis." The analytical techniques adopted during each of these two phases are briefly examined below.

\section{Analyzing Within-Case Data}

Within-case analysis typically involves detailed write-ups for each case. These writeups are often simply pure descriptions, but they are central to the generation of insight because they help researchers to cope early in the analysis process with the often enormous volume of data (Eisenhardt 1989). However, there is no standard format for such analysis. The procedure followed to analyze each of the IT implementation projects in our study is summarized in Table 2.

As a first step, we needed to develop a database for each IT implementation project. The database organized and documented the data collected for each IT implementation project. Each of the three databases (one for each project) contained the following elements: (1) raw material (including interview transcripts, researcher's field notes, documents collected during data collection, and survey material); (2) coded data; (3) coding scheme; (4) memos and other analytic material; (5) data displays; (6) general chronological log of data collection; and (7) document summary forms.

Coding in qualitative research involves segmenting the data into units (Hammersley and Atkinson 1983) and rearranging them into categories that facilitate insight, comparison, and the development of theory (Strauss and Corbin 1990). Codes serve as retrieval and organizing devices which allow the rapid retrieval and clustering of all the segments related to a particular question, concept, or theme. To be consistent with our conceptual framework, the coding scheme developed in our study was divided into three broad categories: (1) contextual conditions, (2) implementation tactics, and (3) implementation success criteria. Appendix 4 shows an excerpt of the coding scheme developed in our study. 
Table 2 Within-Case Analysis Procedure.

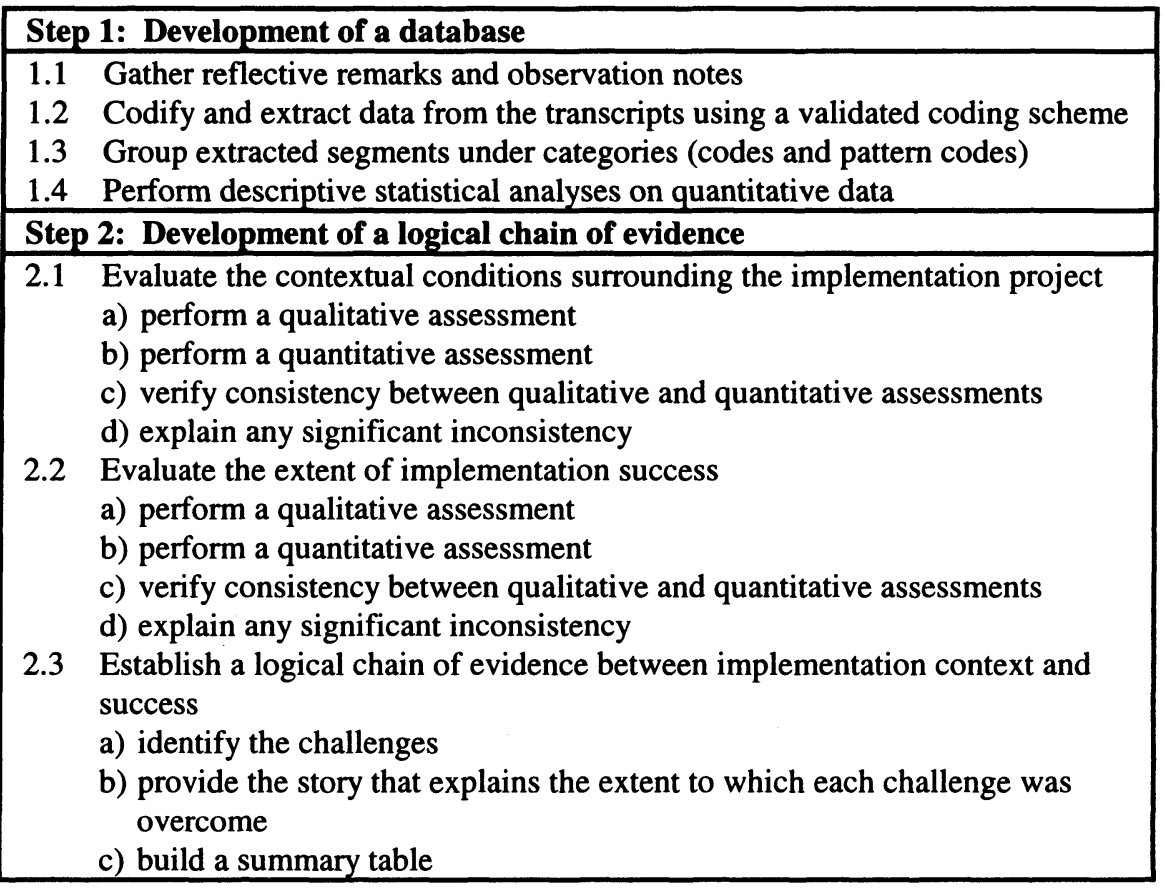

Specific rules had to be established to ensure the reliability of the coding scheme and the overall quality of the coding process. First, an initial list of codes was developed based on our conceptual framework. The original list was then used to codify and extract the data from the transcripts associated with case one. As a result of this process, we found the need to add a few codes. Once all transcripts associated with the first project were codified, two coders were selected to determine inter-rater reliability. After a ten minute initial briefing by the researchers, each coder was instructed to read coding instructions to become acquainted with the coding scheme. Each coder was asked to assign codes to a series of segments representing contextual conditions, implementation tactics and implementation success criteria. The selected segments were randomly selected from all the segments included in the same category. It is worth noticing that the segments used as examples in the instructions were not selected for the validation process. Once each coder completed the task, the researchers' original coding was supplied and each coder was instructed to discuss any differences with the researchers. On a pairwise basis, the coders' responses and the researchers' codes were compared. Results revealed a fairly strong agreement among the coders. 
Although most coding categories are drawn from existing theory or prior knowledge of the setting or system, others can be developed inductively by the interviewer. In addition to predefined codes, our study identified and defined pattern or inferential codes during data analysis (Eisenhardt 1989). Pattern codes are ones that identify an emergent theme, pattern, or explanation that the site suggests to the researcher (Miles and Huberman 1994). Pattern coding is, for qualitative researchers, an analogue to the cluster-analytic and factor-analytic devices used in statistical analysis (Miles and Huberman 1994). Pattern coding served two main functions in our study. First, it reduced large amounts of data into a smaller number of analytic units and, second, it helped us build a cognitive map, an evolving schema for understanding what was happening in each case. Four pattern codes were used in each of the three IT implementation projects analyzed in this study. These codes reflected perceived relationships among constructs included in the conceptual framework. More specifically, these codes reflected: (1) the influence of a contextual condition (e.g., beliefs of key actors) on the way a specific tactic was implemented (e.g., internal integration); (2) the direct influence of a contextual condition (e.g., system complexity) on an aspect of the success of a project (e.g., system acceptance); (3) the effect of a coping tactic (e.g., incremental implementation) on a contextual condition (e.g., users' attitudes); and (4) the direct effect of a coping tactic (e.g., external integration) on an aspect of the success of a project (e.g., project progress).

In order to understand the how and why associated with each IT implementation project and hence to provide answers to our research questions, a logical chain of evidence (Yin 1984) needed to be established. This chain of evidence was built in several steps. The first task was to identify the challenges encountered during the implementation process. Challenges were identified through an in-depth analysis of the contextual conditions surrounding the implementation project. In turn, for each challenge, we described the tactics adopted to cope with the encountered problems, anticipated or not. The extent to which each challenge was overcome was explained by (1) providing evidence of the effectiveness of each coping tactic, (2) identifying and explaining how certain contextual conditions enhanced the effectiveness of coping tactics, and (3) explaining how other conditions prevented the adoption of tactics by acting as compensatory mechanisms. As recommended by Yin, each chain of evidence was established by having sufficient citations in the report to the relevant portions of the case study database and developing a case study protocol that clearly indicates the links between the content of the protocol and the initial research questions.

The adoption of displays such as matrices, flowcharts, and conceptual maps was also useful in several ways during data analysis. For one thing, they made ideas visible and permanent. For instance, besides indicating who has formal authority over whom and what the role names are among actors, context charts (Miles and Huberman 1994) were useful in telling us about the quality of the working relationships between actors (or groups of actors) involved in each IT implementation project. Importantly, these charts showed who the key actors were as well as the role played 
by every individual. Figures and charts also served two other key functions: data reduction and presentation of data that allows it to be grasped as a whole (Miles and Huberman 1994). For instance, checklist matrices were used to synthesize the overall evaluation (qualitative and quantitative) of 1) the implementation situation or context and 2) the extent of implementation success. A short glance at these tables allowed us to clearly identify the challenges that were encountered over the course of each project and the extent of project success. Importantly, comparison of matrices showing qualitative and quantitative evidence revealed a large extent of congruity and consistency between the researchers' and the key informants' evaluations. In sum, the use of displays allowed us to draw and verify valid conclusions because each display was "arranged coherently to permit careful comparisons, detection of differences, noting of patterns and themes, seeing trends" (Miles and Huberman 1994, p. 92).

\section{Searching for Cross-Case Patterns}

As stressed earlier, the ultimate intent of our research was to gradually build a new theory of IT implementation. This iterative process started with the development and presentation of an initial set of theoretical propositions based on evidence from the first IT implementation project and the theoretical assumptions associated with the teleological process meta-theory. The initial propositions then became a vehicle for generalizing to the other two projects. As a second step, the emergent propositions from the first project were systematically compared with evidence from the second project. The theoretical propositions were either supported by the evidence, revised, or not supported for lack of sufficient evidence. As a third and final step, the process was repeated when refined theoretical propositions were systematically compared with evidence from the third project. The central idea was to iterate toward a theory that fits the data, where projects that supported the emergent theory enhance confidence in its validity, while projects that did not support the theory often provide an opportunity to refine and extend the theoretical model (Eisenhardt 1989). Step 6 describes how the series of propositions were derived.

\subsection{Step 6: Shaping Research Propositions}

The next step of this highly iterative process is to compare systematically the emerging theory with the evidence from each project in order to assess how well or poorly it fits with the data. The central idea is that researchers constantly compare theory and data - iterating toward a theory that closely fits the data (Eisenhardt 1989).

Based on the teleological process meta-theory, our study proposed a series of research propositions reflecting the complex and dynamic nature of IT implementation. Each proposition addressed a specific aspect related to the dynamic nature of IT implementation. For instance, the teleological process meta-theory incorporates the systems theory assumption of equifinality; that is, a given end goal can potentially 
be achieved via a number of paths, all tending toward the same endpoint. Importantly, the teleological view stipulates that human agents are rational actors, that is, choices are made based on the actors' beliefs of how likely it is that a particular action or decision will move the process closer to goal achievement. Evidence from all three projects supported both of these contentions. Overall, the seven propositions developed in this study (see Appendix 5) defined a preliminary set of laws of interaction which characterizes the dynamic nature of the IT implementation process. As presently constituted, these propositions are at least one step short of theory formation. At minimum, they are empirical generalizations; that is, they summarize observed uniformities of relationships between predictors and outcomes. At best, they suggest a rudimentary model of IT implementation process.

Again, it is important to note that the above analysis and prescriptions only hold when IT implementation is studied within a teleological view. The adoption of a "dialectical" or an "evolutionary" view would have certainly led to a totally different set of theoretical propositions, since those types of process meta-theories address different aspects of the IT implementation process.

The process of shaping propositions is more judgmental in theory-building research because researchers cannot apply statistical tests. The research team must judge the strength and consistency of relationships within and across cases and also fully display the evidence and procedures when the findings are published, so that readers may apply their own standards. Consequently, qualitative data are particularly useful for understanding why or why not emergent relationships hold. When a relationship is supported, the qualitative data often provide a good understanding of the dynamics underlying the relationship, that is, the why of what is happening. This is crucial in the establishment of internal validity. Consequently, having sufficient citations and quotes in each of the three IT implementation project reports was an important way of ensuring internal validity in our study. Another way of validating researchers' interpretations is by systematically gathering feedback about one's conclusions from participants in the case being studied (Guba and Lincoln 1989). Two tactics were therefore adopted to further increase the validity and reliability of our research. First, the draft of each IT implementation project report was reviewed by key informants. Second, a site analysis meeting for each project took place at the end of data analysis. Participants in these meetings were those in a position to reflect on the project's "big picture."

\subsection{Step 7: Enfolding Literature}

An essential feature of theory building is comparison of the emergent concepts, theory, or hypotheses with the extant literature (Eisenhardt 1989). This involves asking what is it similar to, what does it contradict, and why. In pursuit of this objective, for each proposition, we indicated the extent to which it was supported by previous research and the extent to which we have added some new perspective or new idea when thinking about the management of the IT implementation process. For 
instance, one proposition posits that the selection and effectiveness of implementation tactics and strategies depend on the background, skills, and beliefs of key people involved in the implementation effort. While previous research has acknowledged the importance of having individuals with specific characteristics involved in an implementation effort (Fossum 1986; Schultz, Slevin and Pinto 1987; Hunsucker and Loos 1989; Joshi 1990), our study has shown how these characteristics affect both the selection and effectiveness of various implementation tactics employed. This implies that no one set of normative implementation tactics can or should be applied to all projects. Rather, project leaders should ensure that the implementation tactics adopted complement the experiences, skills, and beliefs brought by each player in the implementation effort.

Another proposition stipulates that successful implementation requires identifying and addressing implementation challenges. This evidence adds support to previous research that has found that most unsuccessful IT implementation projects are the result of poor management, not technical problems (Waldrop 1984; Lyytinen and Hirschheim 1987; Ewusi-Mensah and Przansnyski 1991). While much of the implementation research has equated good management with knowing what to do (Schultz, Slevin and Pinto 1987; Leonard-Barton and Deschamps 1988; Lorenzi and Riley 1995), we suggest that good management must also focus on what to look for and think about. In short, we found that tying the emergent theoretical propositions to existing literature enhances internal validity and generalizability of theory building from case study research as suggested by Eisenhardt.

\subsection{Step 8: Reaching Closure}

An important issue in reaching closure is when to stop adding cases. Ideally, researchers should stop adding cases when theoretical saturation is reached (Eisenhardt 1989). Theoretical saturation is the point at which incremental learning is minimal because the researchers are observing phenomena seen before (Glaser and Strauss 1967). In practice, however, theoretical saturation often combines with pragmatic considerations to dictate when case collection ends. In fact, it is not uncommon for researchers to plan the number of cases in advance.

For pragmatic reasons of time, money, and opportunity, this study involved only three IT implementation projects. Clearly, theoretical saturation cannot be attained with such a small number of cases. Therefore, additional case studies of IT implementation projects must be conducted to increase the validity and reliability of the theoretical propositions developed in our research. The theoretical propositions would benefit not only from being tested in other organizational contexts and using other information technologies but also from being tested against recent project failures where projects were abandoned at some point or where systems were not used at all. 


\section{CONCLUDING REMARKS}

The objective of this article was twofold. First, our aim was to present and critique the methodology for building theories from case study research proposed by Eisenhardt within the context of the MIS field. Our second intent was to describe in some detail how this methodology was applied in a particular research study on IT implementation and how the use of this methodology contributed to the discovery of a number of new perspectives and empirical insights. In light of these objectives, this article makes two contributions to the literature. The first is to operationalize the "roadmap" presented by Eisenhardt and to document the specific decisions that a researcher must make in order to build theories from case study research. The second is to show how previously-defined techniques (e.g., Yin 1984; Miles and Huberman 1984) can be used in applying Eisenhardt's approach.

Little MIS research has been focused on the development of theory. Rather, the MIS field has borrowed heavily from the theories of other disciplines. However, there are numerous IT phenomena in addition to IT implementation whose underlying dynamics are unknown and thus are good candidates to study using a case study research strategy. We hope that we have provided a detailed guide for carrying out such a research strategy.

There is still an issue of legitimacy when conducting qualitative studies. Qualitative studies are gradually becoming more accepted; meanwhile, researchers will have to work harder, be more creative, and come up with new and more robust methodological tools to have their work recognized and accepted in a community that tends to be skeptical of qualitative studies. Applying a well-defined methodology along the lines described in this paper will help to position qualitative studies more in the mainstream of IT research.

It is also important to consider the overall demand of this methodological approach on the researcher. For instance, process research usually results in the collection of large amounts of data vulnerable to subjective interpretation and surpassing human ability to compile. Because of the demands and problems encountered during qualitative research, researchers must have a great interest in and dedication to the object of research (Barley 1990; Leonard-Barton 1990). While it is important to gain the trust and confidence of organizational members, it is also important to remain sufficiently detached so as to be objective. Importantly, researchers should not underestimate the time and effort required to conduct these kinds of studies. From this research it was also learned that one must often be willing to spend lunches, evenings, and weekends collecting data at the site. Despite these constraints, qualitative studies remain, we believe, the best approach available for studying complex phenomena such as IT implementation. The reward clearly appears to be a deeper and broader understanding of IT implementation and the ability to contribute significantly to cumulative knowledge in the field. 


\section{REFERENCES}

Anderson, J. G., and Aydin, C. E. (1994). "Overview: Theoretical Perspectives and Methodologies for the Evaluation of Health Care Information Systems." In J. G. Anderson, C. E. Aydin, and J. J. Stepen (Editors), Evaluating Health Care Information Systems, Methods and Applications. Thousand Oaks, California: SAGE Publications, pp. 5-29.

Barley, S. R. (1990). "The Alignment of Technology and Structure Through Roles and Networks." Administrative Science Quarterly, Volume 35, pp. 61-103.

Benbasat, I.; Goldstein, D. K.; and Mead, M. (1987). "The Case Research Strategy in Studies of Information Systems." MIS Quarterly, Volume 11, Number 3, September, pp. 369-385.

Bonoma, T. V. (1985). "Case Research in Marketing: Opportunities, Problems, and a Process." Journal of Marketing Research, Volume 22, pp. 199-208.

Eisenhardt, K. M. (1989). "Building Theories from Case Study Research." Academy of Management Review, Volume 14, Number 4, pp. 532-550.

Elam, J. J.; Prescott, M.; and Wasala, C. (1994). "Making it Work: How Organizations Succeed in Implementing Emerging Information Technologies." Working Paper, Florida International University.

Ewusi-Mensah, K., and Przasnyski, Z. H. (1991). "On Information Systems Project Abandonment: An Exploratory Study of Organizational Practices." MIS Quarterly, Volume 15, Number 1, March, pp. 67-88.

Fossum, B. (1986). A Normative Model for CIM Implementation. Unpublished Doctoral Dissertation, University of Texas at Austin.

Glaser, B., and Strauss, A. (1967). The Discovery of Grounded Theory: Strategies of Qualitative Research. London: Wiedenfeld and Nicholson.

Guba, E. G., and Lincoln, Y. S. (1989). Fourth Generation Evaluation. Newbury Park, California: Sage.

Hammersley, M., and Atkinson, P. (1983). Ethnography: Principles in Practice. London: Tavistock.

Hunsucker, J. L., and Loos, D. (1989). "Transition Management, an Analysis of Strategic Considerations for Effective Implementation." Engineering Management International, Volume 5, pp. 167-178.

Jick, T. (1979). "Mixing Qualitative and Quantitative Methods: Triangulation in Action." Administrative Science Quarterly, Volume 24, pp. 602-611.

Joshi, K. (1990). "Reorganization of the Work System for Successful Information Systems Implementation: A Case Study." Information and Management, Volume 19, pp. 271-284.

Kaplan, B. (1987). "Initial Impact of a Clinical Laboratory Computer System: Themes Common to Expectations and Actualities." Journal of Medical Systems, Volume 11, pp. 137-147.

Kaplan, B. (1988). "Development and Acceptance of Medical Information Systems: An Historical Overview." Journal of Health and Human Resources Administration, Volume 11, pp. 9-29. 
Kaplan, B. (1993). "The Computer as Rorschach: Implications for Management and User Acceptance." In R. E. Dayhoff (Editor), Proceedings of the Seventh Annual Symposium on Computer Applications in Medical Care. Silver Spring, Maryland: IEEE Computer Society Press, pp. 664-667.

Kaplan, B., and Duchon, D. (1988). "Combining Qualitative and Quantitative Methods in Information Systems Research: A Case Study." MIS Quarterly, December, pp. 571-586.

Kaplan, B., and Maxwell, J. A. (1994). "Qualitative Research Methods for Evaluating Computer Information Systems." In J. G. Anderson, C. E. Aydin, and S. J. Jay (Editors), Evaluating Health Care Information Systems, Methods and Applications. Thousand Oaks, California: Sage Publications, pp. 45-68.

Kochen, M. (1985). “Are MIS Frameworks Premature?” Journal of Management Information Systems, Volume 2, Number 3, Winter 1985-1986, pp. 92-100.

Kwon, T. H., and Zmud, R. W. (1987). "Unifying the Fragmented Models of Information Systems Implementation.” In R. J. Boland and R. A. Hirschheim (Editors), Critical Issues in Information Systems Research. Chichester, England: John Wiley and Sons, Ltd., pp. 227-251.

Lee, A. S. (1989). “A Scientific Methodology for MIS Case Studies.” MIS Quarterly, Volume 13, Number 1, March, pp. 33-52.

Leonard-Barton, D. (1988). "Implementation and Mutual Adaptation of Technology and Organization." Research Policy, Volume 17, Number 5, 1988, pp. 1-17.

Leonard-Barton, D. (1990). “A Dual Methodology for Case Studies: Synergistic Use of a Longitudinal Single Site with Replicated Multiple Sites." Organization Science, Volume 1, Number 3, pp. 248-266.

Leonard-Barton, D., and Deschamps, I. (1988). "Managerial Influence in the Implementation of New Technology." Management Science, Volume 34, Number 10, October, pp. 1252-1265.

Lorenzi, N. M., and Riley, R. G. (1995). Organizational Aspects of Health Informatics: Managing Technological Change. New York: Springer Verlag.

Lucas, H. C. Jr. (1978). "Empirical Evidence For a Descriptive Model of Implementation.” MIS Quarterly, Volume 2, Number 2, June, pp. 27-42

Lucas, H. C. Jr.; Ginzberg, M. J.; and Schultz, R. L. (1990). Information Systems Implementation: Testing a Structural Model. Norwood, New Jersey: Ablex.

Lyytinen, K., and Hirschheim, R. (1987). "Information Systems Failures: A Survey and Classification of the Empirical Literature." Oxford Surveys in Information Technology, Volume 4, pp. 257-309.

Miles, M. B., and Huberman, A. M. (1984). Qualitative Data Analysis. Beverly Hills: Sage Publications.

Miles, M. B., and Huberman, A. M. (1994). Qualitative Data Analysis: An Expanded Sourcebook. Beverly Hills: Sage Publications.

Mohr, L. B. (1982). Explaining Organizational Behavior. San Francisco: JosseyBass.

Newman, M., and Robey, D. (1992). "A Social Process Model of User-Analyst Relationships.” MIS Quarterly, Volume 16, Number 2, June, 249-266. 
Paré, G. (1995). Understanding the Dynamics of IT Implementation: The Case of Clinical Information Systems. Doctoral Dissertation, Florida International University.

Paré, G., and Elam, J. J. (1996). "Understanding the Dynamics of IT Implementation: A Case Study in a Burn Center" Congrès de l'Association des Sciences Administratives du Canada, Montréal, Québec, May 25-28.

Paré, G.; Elam, J. J.; and Lima, C. (Forthcoming). "Implementation of an Electronic Medical Records System: How Can Health Care Managers Ensure its Success?" Journal of Information Technology Management.

Robey, D., and Newman, M. (1996). "Sequential Patterns in Information Systems Development: An Application of a Social Process Model." ACM Transactions on Information Systems, Volume 14, Number 1, January, pp. 30-63.

Robey, D., and Zeller, R. L. (1978). "Factors Affecting the Success and Failure of an Information System for Product Quality." Interfaces, Volume 8, Number 2, February, pp. 70-75.

Sabherwal, R., and Robey, D. (1993). "An Empirical Taxonomy of Implementation Processes Based on Sequences of Events in Information System Development." Organization Science, Volume 4, Number 4, November, pp. 548-576.

Schultz, R. L.; Slevin, D. P.; and Pinto, J. K. (1987). "Strategy and Tactics in a Process Model of Project Implementation." Interface, Volume 17, Number 3, May-June, pp. 34-46.

Srinivasan, A., and Davis, J. G. (1987). "A Reassessment of Implementation Process Models.” Interfaces, Volume 17, Number 3, May-June, pp. 64-71.

Strauss, A. L., and Corbin, J. (1990). Basics of Qualitative Research: Grounded Theory Procedures and Techniques. Newbury Park, California: Sage.

Swanson, E. B. (1974) "Management Information Systems: Appreciation and Involvement." Management Science, Volume 21, pp. 178-188.

Swanson, E. B. (1988). Information System Implementation: Bridging the Gap Between Design and Design and Utilization. Homewood, Illinois: Irwin.

Van de Ven, A. H. (1992). "Suggestions for Studying Strategy Process: A Research Note." Strategic Management Journal, Volume 13, pp. 169-188.

Van de Ven, A. H., and Poole, M. S. (1995). "Explaining Development and Change in Organizations." Academy of Management Review, Volume 20, Number 3, July, pp. 510-540.

Van Maanen, J. (1988). Tales of the Field: On Writing Ethnography. Chicago: University of Chicago Press.

Waldrop, J. H. (1984). "Project Management: Have We Applied All That We Know?" Information and Management, Volume 7, pp. 13-20.

Wynekoop, J. L. (1992). "Strategies for Implementation Research: Combining Research Methods.” In J. I. DeGross, J. D. Becker, and J. J. Elam (Editors), Proceedings of the Thirteenth Annual International Conference on Information Systems. Dallas, Texas, December, pp. 185-193.

Yin, R. K. (1984). Case Study Research: Design and Methods Beverly Hills: Sage Publications. 


\section{BIOGRAPHY}

Guy Paré is assistant professor of information systems at the École des Hautes Études Commerciales in Montréal. He received his Ph.D. in information systems from Florida International University. His research interests center on system implementation, the organizational impacts of IT, and the virtual organization.

Joyce J. Elam is the James L. Knight Professor of Management Information Systems in the Department of Decision Sciences and Information Systems. She was previously an associate professor at the University of Texas and an assistant professor at the University of Pennsylvania's Wharton School. Dr. Elam was a Marvin Bower Fellow at the Harvard Business School during the 1987-1988 academic year. Dr. Elam earned both her Ph.D. in operations research (1977) and her BA in mathematics (1970) from the University of Texas. Dr. Elam has published extensively in the areas of the competitive use of information technology, the management of the information services function, and the use of information technology to support both individual and group decision making.

\section{Appendix 1 \\ Conceptual Framework}

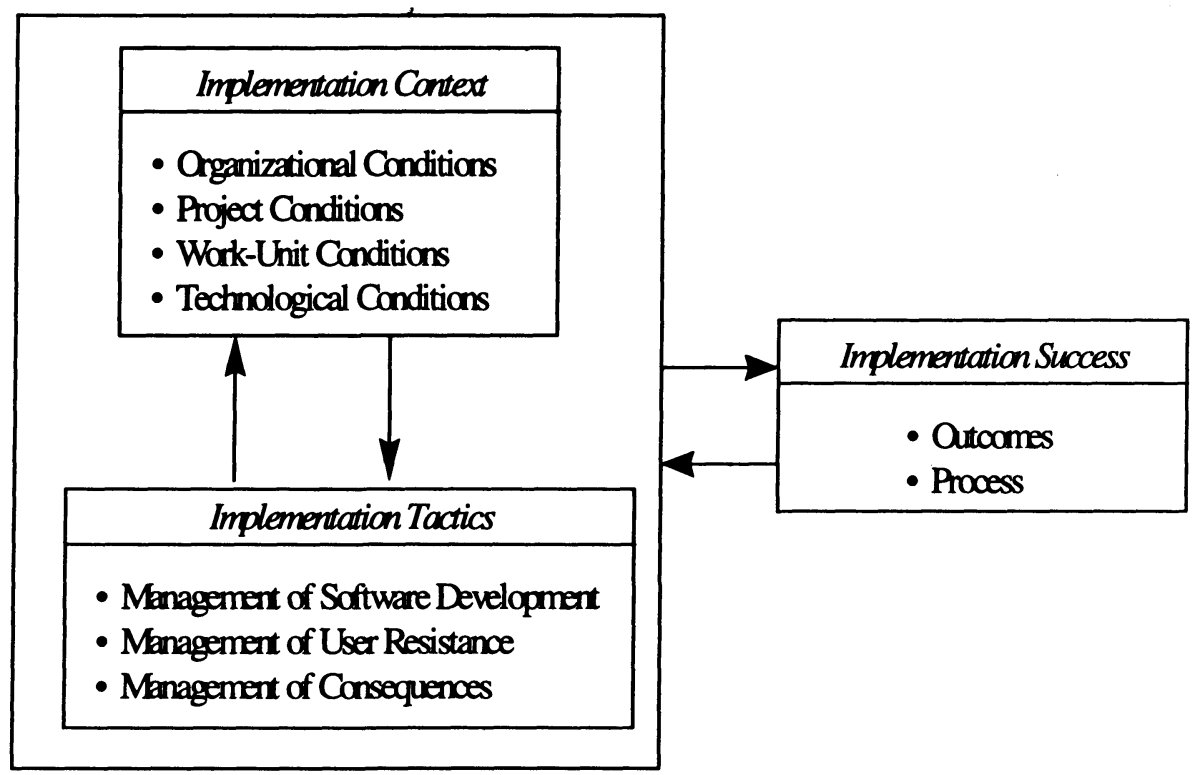




\title{
Appendix 2 \\ Excerpt of an Interview Guide
}

\author{
Interview Guide \# \\ Health Care Center: \\ Unit: Burn Unit \\ Date: 11 \\ Time:
}

\section{INTRODUCTION}

Purpose of the meeting: Learn more about the context in which the implementation of the computerized charting system took place as well as the tactics adopted to ensure system success.

\section{RESPONDENT}

Name: (confidential)

Title:
Phone:

Beeper:

- How long did you work for the Burn Center?

- Which position(s) did you occupy?

\section{IMPLEMENTATION CONTEXT}

Previous experience with IT:

- <The director of the medical unit $>$ told me that prior to using the <second system>, nurses and physicians were using a mainframe-based information system. He also told me that there was reluctance from the staff to use this system in the beginning. How had the transition been from paper-based to computer-based?

- How would you describe the Burn Unit experience with the <first> system implementation? Did you go through "chaos" in the beginning? How has the situation evolved? Did people adjust easily? If so, what made them adjust? Were there specific actions taken at a certain point?

- To what extent would you say the experience with the first system affected the implementation of the second computer system? Explain.

\section{Organizational Climate}

- How would you describe the work environment in the unit? Explain.

- Had you been aware of any major or minor political issue(s) that took place and were debated during the project? If any, ask for details: What? When? Who was involved? Why? 


\section{Organizational Resources}

- In your opinion, has the implementation of the <second> system been supported by enough resources in terms of money, people, and equipment. Explain.

- Has the implementation process been affected by a lack of resources at any point in time?

\section{IMPLEMENTATION TACTICS}

\section{External Integration}

- How have physicians, nurses, and administrators been kept informed of the progress regarding the implementation of the <second > system?

- <Director of Burn Center> mentioned that nursing provided some input in the design of the system. To what extent would you say nursing input was critical? What have been the effects associated with this tactic?

\section{Phased implementation (gradualism)}

- Many argue that the key to getting nurses and docs to use any computer system is gradualism; that if you start with the full implementation of computer chart, it won't work. Would you say that the phased implementation strategy adopted for both the first and the second systems was an effective strategy?

\section{Championing}

- Many argued that any system should be sold to nurses and physicians if they are to use it? How has this happened here in the case of the second system?

- Were the benefits and advantages of the second system over the first system broadly diffused to your staff? Did you emphasize the problems associated with the first system and how the <second > system would solve them?

\section{IMPLEMENTATION SUCCESS}

- Overall, how successful has the use of the <second> system been?

- In your opinion, what have been the major benefits associated with the use of the <second> system, from an individual or nurse standpoint and from an organizational or unit standpoint?

- Ultimately the most significant beneficiary of electronic patient charts should be the patient. Has this been achieved in your case? Explain.

6. AFTERTHOUGHTS AND COMMENTS: (if any) 


\section{Appendix 3}

Profile of the Interviewees

\begin{tabular}{|c|c|c|c|c|}
\hline Case & System & Site & $\begin{array}{l}\text { Interviews with } \\
\text { team members }\end{array}$ & Interviews with users \\
\hline 1 & $\begin{array}{l}\text { Medical } \\
\text { records - } \\
\text { Electronic } \\
\text { signature }\end{array}$ & $\begin{array}{l}\text { Hospital- } \\
\text { wide }\end{array}$ & $\begin{array}{l}\text { Dir. of Medical Records } \\
\text { VP Medical Affairs } \\
\text { HIS coordinator } \\
\text { Education coordinators } \\
\text { Systems analysts } \\
\text { Programmers } \\
\text { Number of interviews: } \\
26\end{array}$ & $\begin{array}{l}\text { Attending physicians * } \\
\text { Nurse liaisons } \\
\text { Medical records staff } \\
\text { Number of interviews: } \\
13\end{array}$ \\
\hline 2 & $\begin{array}{l}\text { Nursing } \\
\text { flowsheet } \\
\text { system }\end{array}$ & $\begin{array}{l}\text { Trauma } \\
\text { Center }\end{array}$ & $\begin{array}{l}\text { Dir. Clinical } \\
\text { Applications } \\
\text { Asst. Dir. Soft. Tech. } \\
\text { Clinical educators } \\
\text { Head nurses } \\
\text { Programmers } \\
\\
\text { Number of interviews: } \\
19\end{array}$ & $\begin{array}{l}\text { Number of interviews: } \\
31\end{array}$ \\
\hline 3 & $\begin{array}{l}\text { Electronic } \\
\text { patient } \\
\text { chart }\end{array}$ & $\begin{array}{l}\text { Burn } \\
\text { Center }\end{array}$ & $\begin{array}{l}\text { Medical Director } \\
\text { Associate Director } \\
\text { Head nurse } \\
\text { Clinical educator } \\
\text { System administrator } \\
\text { Number of interviews: } \\
12\end{array}$ & $\begin{array}{l}\text { Registered nurses * } \\
\text { Physicians } \\
\text { Resident staff } \\
\text { Physical therapists } \\
\text { Dietician } \\
\text { Number of interviews: } \\
25\end{array}$ \\
\hline
\end{tabular}




\section{Appendix 4 Excerpt of the Coding Scheme}

Contextual Conditions

National Movement toward Computerization (EC/NAT_MOV)

A segment which presents evidence of efforts made by national associations, agencies, and hospitals towards computerization.

\section{Organizational Climate (OC/ORG_CLI)}

A segment which reflects one's own perception about his/her organization with respect to commitment to technological and/or management initiatives.

\section{Organizational IT Experiences (OC/IT_EXP)}

A segment which refers to the memories or experiences that exist in the organization about prior information technology initiatives.

\section{Availability of Organizational Resources (OC/AVA_RES)}

A segment which shows the extent to which the organizational resources needed to support the development and implementation of the system were available. Organizational resources do not only include money, but also time, people, hardware, software, and facilities.

\section{Users Skills/Knowledge (WUC/SKILLS)}

A segment which describes one's perception of the extent to which users are familiar with the task being automated, are familiar with the computer system, and/or have experience with computers in general.

\section{Implementation Tactics}

\section{External Integration (SD/EXT_INT)}

A segment which indicates the adoption of tactic(s) whose objective is to link the project team's work to the users. Examples of external integration tactics include the selection of a user as project leader, the selection of particular users as team members, and the consultation of users on an occasional basis for feedback purposes.

\section{Internal Integration (SD/INT_INT)}

A segment which describes the adoption of tactic(s) whose purpose is to ensure that the project team operates as an integrated unit. Well-known internal integration tactics include the selection of experienced IT professionals to be part of the project team; frequent project team meetings; participation of all team members in goal 
setting; and selection of a high percentage of team members with significant previous work experience and relationships.

\section{Championing (SD/CHAMP)}

A segment which illustrates effort(s) made for providing motivation to the project team; generating enthusiasm for the targeted users; providing crucial political support during periods of important decision making; selling the idea to top management; and/or getting senior managers sufficiently interested in the project, etc.

\section{Incremental Approach (UR/INCREM)}

A segment which provides evidence that a strategic decision was to introduce the various modules of the computer system in a gradual, step-by-step manner.

\section{Mutual Adaptation (MC/ADAPT)}

A segment which portrays how the organization moved ahead with the introduction of the technology, left existing organizational arrangements (e.g., structure) in place, and subsequently attended to organizational changes on a responsive or adaptive basis.

\section{Implementation Success Criteria}

\section{System Acceptance and Use (O/ACCEPT_USE)}

A segment which expresses one's perception of users' acceptance and/or use of the computerized information system.

\section{Project Progress (P/PROGRESS)}

A segment which provides insights as for how the project evolved or progressed over time. Most IT implementation or development processes are usually evaluated in terms of their respect of deadlines and budgets. IT projects are also subject to unavoidable or unexpected problems of all sorts.

\section{Overall Satisfaction with the Implementation Process (P/SATIS)}

A segment which makes a suggestion about one's own satisfaction, perception, reflection, and/or evaluation in regard with the overall development and implementation process. 


\section{Appendix 5 Research Propositions}

Proposition \#1: Pragmatism. The successful implementation of computer-based information systems represents a purposeful process where key actors socially construct envisioned end goals, anticipate challenges ahead, and recognize the presence of and capitalize on opportunities.

Proposition \#2: Equifinality/Rationality/Complementarity. The implementation of a computer-based information system is characterized by the systems theory of equifinality; that is, there are likely several equally effective ways to achieve a given end goal. The selection of a particular course of action is a rational process largely influenced by the degree to which key actors can recognize the mediating role of each tactic, can conceive of an alternative beyond the selected course of action, and are motivated to action. Consequently, greater complementarity of key actors' skills and interests is likely to favor a higher quality and more effective implementation strategy.

Proposition \#3: Duality of Structure. Key actors' beliefs regarding a course of action that should be adopted are influenced by the contextual conditions which surround a given project. Yet, through the action of reflective actors, effective implementation tactics are likely to become established as standardized practices while ineffective courses of action are likely to be quickly abandoned.

Proposition \#4: Supporting Mechanisms. The effectiveness of any given implementation tactic is likely to be enhanced when complemented or supported by the presence of one (or many) contextual conditions.

Proposition \#5: Compensatory Mechanisms. Certain favorable contextual conditions surrounding a given implementation project might have a direct effect on its success when acting as compensatory mechanisms.

Proposition \#6: Envisioned End Goals and States of "Rest." Actors' decisions and actions are not all independent of each other and hence their order matters in achieving success. The implementation process can be characterized as a movement where temporary states of "rest" are reached and envisioned end goals are ultimately fulfilled. The fulfillment of any envisioned end goal or state of "rest" constitutes a necessary condition but not sufficient condition for success.

Proposition \#7: Indeterminacy. The implementation of a computer-based information system is characterized by a certain indeterminacy first reflected through the occurrence of unexpected challenges caused by either uncontrollable events or loose implementation practices. This indeterminacy also means that the implemented system might not have all the effects originally envisioned by key actors or might produce unexpected and undesirable consequences. 